\title{
Evaluation of color change using CIE LAB coordinates on tooth structure subjected to different concentrations of peroxide carbamide
}

\author{
Gerardo Durán ${ }^{1 *}$, Felipe Salas ${ }^{1}$, Sandra Gajardo ${ }^{1}$, Christopher Morales $^{1}$, Ismael Henríquez ${ }^{1}$, Luis Barrios ${ }^{1}$, Fernando Rosales ${ }^{1}$
}

\author{
1. Facultad de Ciencias de la Salud, Universidad \\ Arturo Prat, Iquique, Chile.
}

* Corresponding Author: Gerardo Durán | Avenida Arturo Prat 2120, Universidad Arturo Prat, lquique, Chile | Phone: +56972115778 |

E-mail: gerardo.duran@unap.cl

Work received on 23/01/2018.

Approved for publication on 10/02/2018

\begin{abstract}
Aim: The aim of this study was to evaluate the optical behavior of tooth color using CIE $L^{*} A^{*} B^{*}$ space; the teeth were subjected to novel bleaching gels containing peroxide carbamide with potassium oxalate. Materials and Method: Three different carbamide peroxide gels were experimentally fabricated. They consisted of 10\% (G10), 16\% (G16) and $37 \%$ (G37) concentrations. Sixty recently extracted premolars were subjected to different bleaching protocols. Color change $(\Delta E)$ was assessed using the $C I E L^{*} a^{*} b^{*}$ system after the application of each gel. The data were analyzed using one-way ANOVA with Tukey's post hoc test $(\alpha=5 \%)$ and a t-test. Results: The $\mathrm{G} 10$ and $\mathrm{G} 16$ gels exhibited an increase in $\Delta \mathrm{E}^{*} \mathrm{ab}$ parameters from $\mathrm{T0}$ to $\mathrm{T} 1$ (T0: application day of the gels. T1: $14^{\text {th }}$ day measurement); a small decrease from T1 to T2 was also noted (T2: control measurement, $28^{\text {th }}$ day). However, no statistically significant differences were found ( $p=0,22$ for $\mathrm{G} 10$ and $p=0,10$ for $\mathrm{G} 16$ ). The $\mathrm{G} 37 \mathrm{gel}$ also exhibited an increase in $\Delta E^{*}$ ab parameters, with similar results after the first application of $45 \mathrm{~min}$, the second application of $45 \mathrm{~min}$, and the third application of $45 \mathrm{~min}$ (T1, T2 and T3, respectively. T4: control measurement, $14^{\text {th }}$ day). No statistically significant differences were observed between the three times of application $(p>0,69)$, and an appreciable difference was noted between times T3 and T4 $(p=0,000)$. Conclusions: The presented formulations of peroxide carbamide at $10 \%, 16 \%$, and $37 \%$ are clearly effective. The G10 and G16 gels exhibited better effectiveness than the G37 gel.

\section{KEY WORDS}

Peroxide carbamide; Tooth bleaching.
\end{abstract}

Rev. Clin. Periodoncia Implantol. Rehabil. Oral Vol. 11(3); 143-146, 2018.

\section{INTRODUCTION}

Tooth color is the result of the interaction of light with the different hard tissues that compose the tooth structure. When light reaches the tooth surface, many optical phenomena occur. Some portion of the light can be reflected as specular or diffuse light, and another portion is absorbed, dispersed or transmitted. The final result is that the observer perceives color. ${ }^{(1,2)}$

Many intrinsic color changes can be modified by using different tooth bleaching products. Most of these products are based on an active ingredient of hydrogen peroxide present in different concentrations. The mechanism by which the bleaching occurs is not yet well understood, but it is generally associated with an oxidative reaction. During the reaction, the hydrogen peroxide dissociates into radical oxygen and water, and the oxygen can penetrate the tooth enamel and dentine. There, it interacts with acquired molecules of high molecular weight known as "chromophores". These pigmented organic molecules can be composed of aromatic double bonds or metallic bioorganic complexes such as chelator compounds. When the reactive oxygen reaches the organic kind chromophores they can be converted into a simpler structure by reacting over the double bonds via an oxidative process. The absorption spectrum of light from a tooth is accordingly modified, and the luminosity is changed to a higher value. In the case of metallic compounds, this is more complex, requiring more invasive dental restorative treatments. ${ }^{(3,4,5,6,7)}$

Carbamide peroxide is a compound based on hydrogen peroxide associated with urea. Urea is used to stabilize the peroxide and elevates the $\mathrm{pH}$ during treatment. The association of this product with Carbopol, a carboxymethylene polymer that is responsible for part of the gelling aspect of peroxide carbamide, boosts the adherence and viscosity of the peroxide, increasing the release time of the active oxygen. These changes permit peroxide carbamide to be used over longer periods of time as night-guard bleaching products. ${ }^{(5,8,9)}$

Different concentrations have been used since carbamide peroxide was first introduced as a bleaching material..$^{(9,10,11)}$ Some authors ${ }^{(12,13)}$ have reported the use of $10 \%, 16 \%$ and other concentrations under the same application protocols. ${ }^{(14,15)}$ Since no clear protocols have been established for tooth bleaching based on the effectiveness for 10, 16 and $37 \%$ carbamide peroxide, this study aims to evaluate the optical behavior of CIE $L^{*} A^{*} B^{*}$ parameters of tooth color subjected to novel bleaching gels containing peroxide carbamide applied under laboratory conditions at different concentrations.

\section{MATERIAL AND METHOD}

\subsection{Development of Bleaching Gels}

Three formulations of bleaching gels were developed. The elaboration was made by mixing $0,1 \%$ methylparaben (Aldrich ${ }^{\circledR}$ ), $0,1 \%$ sodium benzoate $\left(\right.$ Merck $\left.^{\circledR}\right), 3 \%$ potassium oxalate $\left(\right.$ Fisher $\left.^{\circledR}\right)$, and peroxide carbamide at $10 \%, 16 \%$ and $37 \%\left(\right.$ Merck $\left.^{\circledR}\right)$, respectively. To produce a complete formulation, sterile distilled water was used. Finally, Carbomer 940 at $2 \%$ and triethanolamine $\left(\right.$ Reutter $\left.^{\circledR}\right)$ were added under agitation. Pre-formulation studies were carried out in which the selected raw materials yielded the product with the desired characteristics. The following physical-chemical characterization tests were then carried out:

\subsection{Organoleptic and physico-chemical parameters}

The gels were stored according to the Chilean climatic zona, which is zone $\mathrm{n}^{\circ} 2$, Mediterranean climate, at $25^{\circ} \mathrm{C}$ and $60 \%$ relative humidity $(\mathrm{RH})$. To keep them from drying out, the gels were stored in hermetically sealed containers that contained a wetting agent that prevented water evaporation via the formation of hydrogen bonds.

\subsection{1.- Organoleptic characteristics:}

Color, odor and texture were evaluated by a panel of five experts. To carry out the organoleptic tests, a reference or standard sample maintained under controlled environmental conditions was used. Color was evaluated by visual means, smell was evaluated through smell and 
texture was evaluated through touch. These measurements were made $0,1,2,3,6$ and 12 months.

\subsubsection{Apparent viscosity:}

The samples were analyzed in a Brookfiel Viscosimeter (Splindle $06)$ at $100 \mathrm{rpm}(10 \%$ and $16 \%$ peroxide carbamide) and $60 \mathrm{rpm}(37 \%$ peroxide carbamide). The apparent viscosity values were registered after $24 \mathrm{~h}$ of gel preparation.

\subsection{3. $\mathrm{pH}$ value:}

The $\mathrm{pH}$ of each formulation was determined by a Hanna $\mathrm{pH}$-meter at room temperature over the course of 12 months. Formulations with variations in $\mathrm{pH}$ value exceeding $15 \%$, compared with the initial value, were removed from the sample.

\subsubsection{Microbiological analysis:}

The samples were seeded on Müeller-Hinton agar. The Petri dishes were incubated at $37^{\circ} \mathrm{C}$, and the bacteria colonies were counted after 24, 48 and 72 hours. The final product did not have to be sterile and no specific pathogens were found (e.g., Escherichia coli, Pseudomona auroginosa, Salmonella spp, Staphylococcus aureus).

\subsubsection{Stability studies:}

Duplicate samples were stored for 12 months at $40 \pm 2^{\circ} \mathrm{C}$ and $75 \%$ $\mathrm{RH}$ (accelerated stability) and at room temperature $\left(25 \pm 2^{\circ} \mathrm{C}\right)$ and $60 \%$ $\mathrm{RH}$ avoiding exposure to light.

\subsection{Effectiveness Evaluation}

Sixty premolars recently extracted due to orthodontics and free of tooth decay or restorations were used. Three groups of 20 teeth each were selected for each formulation (G10, G16 and G37) (carbamide peroxide at 10,16 and $37 \%$, respectively) and stored in artificial saliva at $37^{\circ} \mathrm{C}$. After 24 hours of storage, initial color according to CIE L*a*b was assessed using a spectrophotometer VITA Easyshade Advanced 4.0 (VITA - North America).

According to the International Commission on Ilumination, $L^{*}$ represents the darkness-lightness coordinate or value from the Munsell's Dimensions of Color, $a^{*}$ represents the chromaticity between green (negative $a^{*}$ ) and red (positive $a^{*}$ ), and $b^{*}$ represents the chromaticity between blue (negative $b^{*}$ ) and yellow (positive $\left.b^{*}\right) .^{(17)}$

Two different protocols for tooth bleaching were applied. The G10 and G16 groups received carbamide peroxide at $10 \%$ and $16 \%$, respectively, over the course of 2 hours per day for 14 days. On the 14 th day, color measurements were obtained for both groups. These measurements were repeated after 14 days due to residual oxygen and color stabilization. For the G37 group, three applications of $37 \%$ peroxide carbamide of 45 minutes each were conducted on the same day; after the third application, a color measurement was performed. After 14 days a final tabulation was made to account for residual oxygen and color stabilization.

For the color measurements, the color difference $(\Delta \mathrm{E})$ was calculated using the following formula:

$\Delta \mathrm{E}^{*} \mathrm{ab}=\left[\left(\Delta \mathrm{L}^{*}\right)^{2}+\left(\Delta \mathrm{a}^{*}\right)^{2}+\left(\Delta \mathrm{b}^{*}\right)^{2}\right]^{0,5}$

where

$\Delta L^{*}=L^{*} 1-L^{* 0}$ (measurement after bleaching minus before bleaching)

$\Delta a^{*}=a^{*} 1-a^{* 0}$ (measurement after bleaching minus before bleaching)

$\Delta b^{*}=b^{* 1}-b^{* 0}$ (measurement after bleaching minus before bleaching)

\subsection{Statistical Analysis}

The data were processed using Microsoft Excel ${ }^{\circledR}$ (IBM SPSS Statistics 20.0 and GraphPad Prism $6^{\circledR}$ ). The results were statistically analyzed using one-way analysis of variance (ANOVA) with Tukey's post-hoc test at a $5 \%$ level of significance and a t-test.

\section{RESULTS}

\subsection{Organoleptic and physico-chemical parameter results}

The organoleptic control showed similar results in the three groups, being these translucent and colorless, odorless, with firm texture, compact and with acceptable thixotropic characteristics.

The viscosity in G10, G16 and G37 was 6780, 7730 and $16850 \mathrm{cP}$ respectively. There is no standard for viscosity values in gels for dental bleaching products.

The $\mathrm{pH}$ values resulted in the following means: $\mathrm{G} 10 \mathrm{pH}=4,75 ; \mathrm{G} 16$ $\mathrm{pH}=5,09$ and $\mathrm{G} 37 \mathrm{pH}=5,35$.

No colonies of bacteria or fungi were obtained in the microbiological control, which shows that the selection of the preservatives and their respective concentrations were adequate.
The results of the stability tests were satisfactory; in shelf stability tests, changes were seen after 8 months, where there was a slight change in coloration. In the accelerated stability tests the changes appeared at 6 months, where there was dehydration due to extreme storage conditions.

\subsection{Effectiveness Results}

Tooth color parameters $\left(\Delta \mathrm{L}^{*}, \Delta \mathrm{a}^{*}, \Delta \mathrm{b}^{*}\right.$ y $\left.\Delta \mathrm{E}^{*} \mathrm{ab}\right)$ for the treatment groups at different carbamide peroxide concentrations are listed in Table 1 (G10 and G16) and Table 2 (G37). This information was used to generate graphical statistics. Figure 1 shows the $\Delta E^{*}$ ab differences over time for the G10 and G16 groups. Both groups demonstrated an increase in the $\Delta E^{*}$ ab parameter from $T 0$ to $T 1$. Although a 0,83 and 2,07 decrease was noted for the G10 and G16 groups, respectively, observed between the $14^{\text {th }}$ and $28^{\text {th }}$ days of the control measurement, no statistically significant differences were found according to a t-test

Table 1. $\Delta \mathrm{L}^{*}, \Delta \mathrm{a}^{*}, \Delta \mathrm{b}^{*}$ and $\Delta \mathrm{E}^{*}$ ab parameters of $\mathrm{G} 10$ and $\mathrm{G} 16$ groups.

\begin{tabular}{|c|c|c|c|c|}
\hline \multirow{2}{*}{$\begin{array}{l}\text { Color } \\
\text { Parameters }\end{array}$} & \multicolumn{4}{|c|}{$\begin{array}{l}\text { Evaluation Period: Average value of color changes with } \\
\text { regard to the base line. }\end{array}$} \\
\hline & T0 & T1 & T2 & $\mathrm{p}_{14-28 \text { days }}$ \\
\hline \multicolumn{5}{|l|}{$\Delta \mathrm{L}^{*}$} \\
\hline G10 & 82,94 & 4,23 & 2,85 & 0,087 \\
\hline G16 & 80,76 & 4,19 & 5,01 & 0,543 \\
\hline $\begin{array}{l}\text { P Value } \\
10-16\end{array}$ & 0,121 & 0,971 & 0,058 & \\
\hline \multicolumn{5}{|l|}{$\Delta \mathrm{a}^{*}$} \\
\hline G10 & $-0,32$ & $-2,06$ & $-1,84$ & 0,429 \\
\hline G16 & 1,13 & $-2,76$ & $-2,98$ & 0,745 \\
\hline$P \underset{10-16}{\text { Value }}$ & 0,025 & 0,188 & 0,023 & \\
\hline \multicolumn{5}{|l|}{$\Delta b^{*}$} \\
\hline G10 & 19,66 & $-2,81$ & $-2,77$ & 0,987 \\
\hline G16 & 25,62 & $-10,4$ & $-7,87$ & 0,044 \\
\hline P value & 0,003 & 0,001 & 0,002 & \\
\hline \multicolumn{5}{|l|}{$\Delta \mathrm{E}^{*} \mathrm{ab}$} \\
\hline G10 & - & 8,38 & 7,55 & 0,207 \\
\hline G16 & - & 12,21 & 10,13 & 0,200 \\
\hline$P \underset{10-16}{\text { Value }}$ & - & 0,013 & 0,041 & \\
\hline
\end{tabular}

TO: time of measure at base line; T1: measurement at 14th day; and T2: measurement at 28th day.

Table 2. $\Delta \mathrm{L}^{*}, \Delta \mathrm{a}^{*}, \Delta \mathrm{b}^{*}$ and $\Delta \mathrm{E}^{*}$ ab parameters of $\mathrm{G} 37$ group concentration.

\begin{tabular}{|c|c|c|c|c|c|c|}
\hline \multirow{2}{*}{$\begin{array}{l}\text { Color } \\
\text { Parameters }\end{array}$} & \multicolumn{6}{|c|}{$\begin{array}{l}\text { Evaluation Period: Average value of color changes } \\
\text { with regard to the base line }\end{array}$} \\
\hline & TO & T1 & T2 & T3 & T4 & $\underset{\text { 45min-14th day }}{\text { pValue }}$ \\
\hline \multicolumn{7}{|l|}{$\Delta L^{*}$} \\
\hline G37 & 80,77 & $-0,25$ & 2,85 & $-0,59$ & 2,09 & 0,0014 \\
\hline \multicolumn{7}{|l|}{$\Delta a^{*}$} \\
\hline G37 & 0,15 & 0,47 & $-1,84$ & 0,13 & $-1,55$ & $<0,0001$ \\
\hline \multicolumn{7}{|l|}{$\Delta \mathrm{b}^{*}$} \\
\hline G37 & 24,57 & 0,59 & $-2,77$ & $-0,24$ & $-5,21$ & $<0,0001$ \\
\hline \multicolumn{7}{|l|}{$\Delta \mathrm{E}^{*} \mathrm{ab}$} \\
\hline G37 & - & 3,20 & 2,45 & 2,81 & 6,41 & $<0,0001$ \\
\hline
\end{tabular}

T0: Time at base line. T1: Measurement after first application; T2: Measurement after second application; T3: Measurement after third application. T4: Measurement at 14th day. 


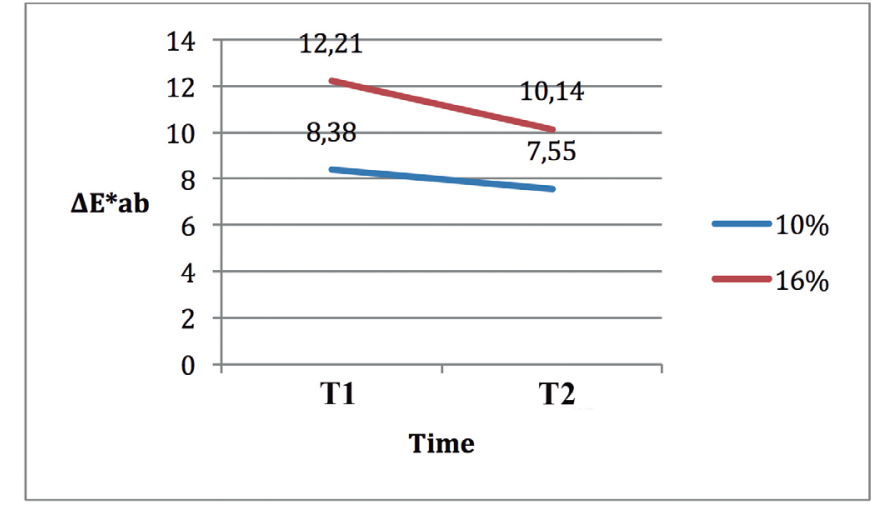

Figure 1. $E^{\star} a b$ of $\mathrm{G} 10$ and $\mathrm{G} 16$ groups over time. T1: 14th day measurement, T2: 28th day measurement.

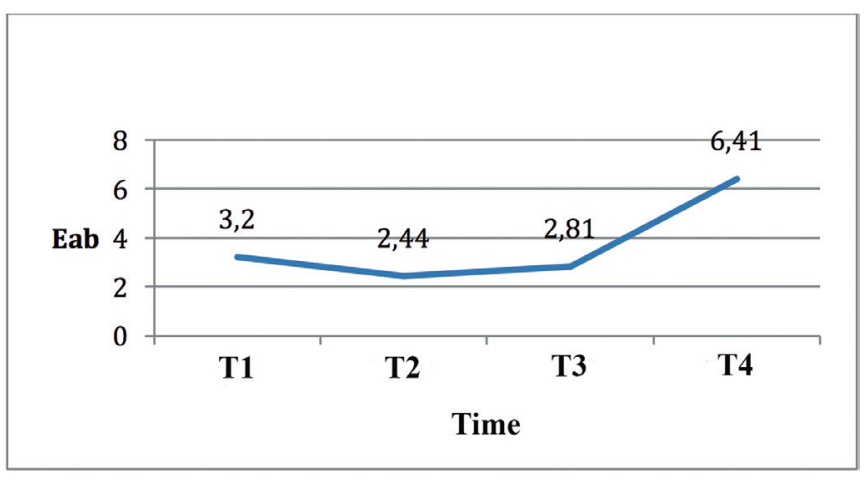

Figure 2. E*ab of G37 group over time. T1: Measurement after first application; T2: Measurement after second application; T3: Measurement after third application. T4: Measurement at the 14th day.

( $p=0,22$ for $\mathrm{G} 10$ and $\mathrm{p}=0,10$ for $\mathrm{G} 16$ ). Figure 2 shows the $\Delta \mathrm{E}^{*} \mathrm{ab}$ of the G37 group, which was similar between the first three times of application (T1, T2 and T3); there were no statistically significant differences $(p>0,69)$. There was a smaller increase in $\Delta E^{*}$ ab from $T 0$ to T1 for the G37 teeth than the G10 and G16 teeth. The ANOVA test revealed statistically significant differences between the first day of bleaching application $(p=0,000)$ and the $14^{\text {th }}$ day; an increase of 3,6 could be observed from T3 to T4.

\section{DISCUSSION}

Hydrogen peroxide is the most commonly used active compound of bleaching gels - it is the active ingredient of every carbamide peroxide gel. ${ }^{(16)}$ It has been shown to be an effective bleaching material whose effectiveness depends on many factors such as the concentration of the active compound and the time of application and duration of the treatment. Furthermore, it is not harmful to dental structures used by a dental professional. ${ }^{(17)}$ Different concentrations of the peroxide gels were successfully formulated and tested by organoleptic tests. Organoleptic tests are procedures used to evaluate the characteristics of a product, detectable by the sense organs. They provide parameters that make it possible to immediately assess the state of the sample under study through comparative analysis, with the aim of verifying alterations such as phase separation, precipitation and turbidity. These data enable the primary recognition of the product. ${ }^{(18)} \mathrm{A}$ comparative analysis among the concentrations was hindered by the different times of application that were required, particularly for the $37 \%$ concentration. Even so, the $10 \%$ and $16 \%$ concentrations could be compared because the same protocols were used. Currently, there is no standard values for $\mathrm{pH}$ and viscosity for the formulation of bleaching gels. Although, according to some studies, ${ }^{(19,20)}$ the $\mathrm{pH}$ values would not produce a potential dental damage or sensitivity. As a recommendation, we suggest limiting the $\mathrm{pH}$ range above 5,5 to avoid possible damage of the enamel matrix.

The $10 \%$ and $16 \%$ peroxide carbamide concentrations demonstrated equal effectiveness in this study, findings confirmed by other studies..$^{(22,23)}$ The $\Delta \mathrm{L}^{*}$ parameter significantly increased, and $\Delta \mathrm{a}^{*}$ and $\Delta \mathrm{b}^{*}$ decreased. These results are consistent with those of the study of Meireles et al.,(17) where the same concentrations of peroxide carbamide were used. This can be clinically appreciated as a higher value or lightness and less chromaticity, which is one of Munsell's dimensions of color associated with a tooth structure with a whiter optical appearance. $\Delta \mathrm{E}^{*} \mathrm{ab}$, which is color change, was maintained after the period of application. Although there was a small decrease, this change was not statistically significant. Color was accordingly stable, and $\mathrm{L}^{*}$ values were maintained, proving that the $10 \%$ and $16 \%$ concentrations were effective.

The $37 \%$ concentration does not exhibit a significant increase in $L^{*}$ during the first three applications. However, at T4 (the control measure at the $14^{\text {th }}$ day), an evident increase in $\Delta \mathrm{E}^{*}$ ab was noted. This color change might have been due to residual oxygen in the tooth structure, which continued to be active and disrupted the chromophores found in areas where oxygen was still present, stabilizing color in approximately 14 days. . $^{(23,24,25)}$

In the present study, the effectiveness of every carbamide peroxide concentration has been proven. Nevertheless, our results indicated that the $10 \%$ and $16 \%$ concentration exhibited clearly better performance and stability of the CIE LAB coordinates compared with the $37 \%$ formula. In vitro outcomes exhibited similar changes in $\Delta \mathrm{E}^{*} \mathrm{ab}$ and $\mathrm{L}^{*}$ values. Because the concentration of hydrogen peroxide increases in higher concentrations of peroxide carbamide formulations, tooth sensitivity may increase during treatment. In the present formulas, potassium oxalate at a level of $3 \%$ was incorporated; this compound reduces $98 \%$ of tooth sensitivity via a simple mechanism in which the oxalate reacts with calcium ions of the dentine, creating new oxalate crystals inside dentinal tubules and the surrounding dentin, which increases the sealing of the dentin surface that makes a mechanical barrier that protects the pulp. ${ }^{(26,27)}$ Bernandon et al. ${ }^{(27)}$ found that concentrations of $10 \%$ and $16 \%$ peroxide carbamide including $3 \%$ potassium oxalate combined with fluoride were not associated with tooth sensitivity. Although the analysis of tooth sensitivity was not an objective of this study, other clinical studies must be conducted to prove tooth sensitivity because the formulations of peroxide carbamide used in this study did not contain fluoride ions.

\section{CONCLUSION}

Within the limitations of the present study, we have shown that 10,16 and $37 \%$ peroxide carbamide changes $\Delta E^{*} a b$, increases $L^{*}$, decreases $\Delta a^{*}$ and $\Delta b^{*}$ of the CIE $L^{*} a^{*} b$ color parameters, improves tooth lightness and reduces its chromaticity or saturation.

\section{ACKNOWLEDGEMENT}

The authors want to thank the Internal Financing of Arturo Prat University of Iquique, Chile, Code VRIIP0094-15, for its support and encourage research.

\section{FUNDING SOURCE}

The following manuscript is the result of a Research Project titled: "Evaluation of color change using CIE LAB coordinates on tooth structure subjected to different concentrations of peroxide carbamide", which was developed under the Internal Initiation Funding of Universidad Arturo Prat, code VRIIP0094-15, exempt decree n¹941, 20th October 2015, Iquique, Chile.

\section{CONFLICTS OF INTEREST.}

The authors declare that they have no conflicts of interest. 


\section{References}

1. Dietschi D. Optimizing smile composition and esthetics with resin composites and other conservative esthetic procedures. Eur J Esthet Dent. 2017;3(1):274-289. 2. Hirata R. Tips: Claves en odontología estética. Buenos Aires: Médica Panamericana; 2012.

3. Eimar H, Siciliano R, Abdallah M, Nader S, Amin W, Martinez P et al. Hydrogen peroxide whitens teeth by oxidizing the organic structure. J Dent. 2012;40:e25-33.

4. Kwon S, Wertz P. Review of the mechanism of tooth whitening. J Esthet Restor Dent. 2015;27(5):240-257.

5. Alqahtani M. Tooth-bleaching procedures and their controversial effects: A literature review. Saudi Dent J. 2014;26(2):33-46.

6. Carey C. Tooth whitening: What we now know. J Evid Based Dent Pract. 2014;14:70-76.

7. Soares D, Ribeiro A, Sacono N, Coldebella C, Hebling J, de Souza Costa C. Transenamel and transdentinal cytotoxicity of carbamide peroxide bleaching gels on odontoblast-like MDPC-23 cells. Int Endod J. 2010;44(2):116-125.

8. de Martini Bonesi C, Storchi Ulian L, Belem P, Weiss Angeli V. Carbamide peroxide gel stability under different temperature conditions: is manipulated formulation an option?. Braz J Pharm Sci. 2011;47(4):719-724.

9. Haywood V. Nightguard vital bleaching: Current concepts and research. J Am Dent Assoc. 1997;128(1):19-25.

10. Oltu U, Gurgan S. Effects of three concentrations of carbamide peroxide on the structure of enamel. J Oral Rehabil. 2000;27(4):332-340.

11. Basting RT, Rodrigues AL Jr, Serra MC. The effects of seven carbamide peroxide bleaching agents on enamel microhardness over time. J Am Dent Assoc. 2003;134(10):1335-1342.

12. Matis B, Gaiao U, Blackman D, Schultz F, Eckert G. In vivo degradation of bleaching gel used in whitening teeth. J Am Dent Assoc. 1999;130(2):227-235.

13. Cardoso PC, Reis A, Loguercio A, Vieira LC, Baratieri LN. Clinical effectiveness and tooth sensitivity associated with different bleaching times for a 10 percent carbamide peroxide gel. J Am Dent Assoc. 2010;141(10):1213-20.

14. Meireles S, Santos I, Bona A, Demarco F. A double-blind randomized clinical trial of two carbamide peroxide tooth bleaching agents: 2-year follow-up. J Dent. 2010:38(12);956-963.

15. Meireles S, Heckmann S, Santos I, Della Bona A, Demarco F. A double blind randomized clinical trial of at-home tooth bleaching using two carbamide peroxide concentrations: 6-month follow-up. J Dent. 2008;36(11):878-884.
16. Tredwin CJ, Naik S, Lewis NJ, Scully C. Hydrogen peroxide tooth-whitening (bleaching) products: review of adverse effects and safety issues. Br Dent $\mathrm{J}$. 2008;200(7): 371-376.

17. Meireles S, Fontes S, Coimbra L, Bona Á, Demarco F. Effectiveness of different carbamide peroxide concentrations used for tooth bleaching: an in vitro study. J Appl Oral Sci. 2012;20(2):186-191.

18. Meireles S, Heckmann S, Leida F, dos Sanos Ida S, Della Bona A, Demarco F. Efficacy and safety of $10 \%$ and $16 \%$ carbamide peroxide tooth-whitening gels: a randomized clinical trial. Oper Dent. 2008;33(6):606-612.

19. Price RB, Sedarous M, Hiltz GS. The $\mathrm{pH}$ of tooth-whitening products. J Can Dent Assoc. 2000;66(8):412-426.

20. Majeed A, Grobler SR, Moola MH. The $\mathrm{pH}$ of various tooth-whitening products on the South African market. SADJ. 2011;66(6):278-281.

21. Meireles S, dos Santos Ida S, Della BonaA, Demarco F. Adouble-blind randomized controlled clinical trial of 10 percent versus 16 percent carbamide peroxide toothbleaching agents: one-year follow-up. J Am Dent Assoc. 2009;140(9):1109-1117.

22. Sulieman MA. An overview of tooth-bleaching techniques: chemistry, safety and efficacy. Periodontol 2000. 2008;48(1):148-169.

23. Guasso B, Salomone P, Nascimiento PC, Pozzobon RT. Release time of residual oxygen after dental bleaching with $35 \%$ hydrogen peroxide: effect of a catalasebased neutralizing agent. Gen Dent. 2016;64(3):56-59.

24. Pimentel A, Valente L, Isolan C, Münchow E, Piva E, de Moraes R. Effect of waiting time for placing resin composite restorations after bleaching on enamel bond strength. Appl Adhes Sci. 2015;3(1):23

25. Miglani S, Aggarwal V, Ahuja B. Dentin hypersensitivity: Recent trends in management. J Conserv Dent. 2010;13(4):218-224.

26. Camilotti V, Zilly J, Busato P, Nassar C. Nassar P. Desensitizing treatments for dentin hypersensitivity: a randomized, split-mouth clinical trial. Braz Oral Res. 2017;26(3):263-268.

27. Bernardon J, Vieira Martins M, Branco Rauber G, Monteiro Junior S. Baratieri L. Clinical evaluation of different desensitizing agents in home-bleaching gels. J Prosthet Dent. 2016;115(6):692-696. 